\title{
Massive Hematuria in the Heterozygous Sickle Cell Disease: A Report of Two Cases
}

\section{Ndéye Aïssatou BAGAYOGO ${ }^{1}$, Babacar SINE ${ }^{1,2}$, Mbaye DIAW ${ }^{1}$, Amath THIAM ${ }^{1}$, Babacar DIAO' ${ }^{1}$ and Alain Khassim NDOYE ${ }^{2}$}

${ }^{1}$ Urology Andrology Department, Ouakam Military Hospital, Senegal

${ }^{2}$ Urology Andrology Department, Aristide Le Dantec Hospital, Senegal

*Corresponding author: Dr. Babacar Sine, Urology Andrology Department, Ouakam Military Hospital, Dakar, Senegal; Urology Andrology Department, Aristide Le Dantec Hospital, Dakar, Senegal, Tel: 00221-774437657

\begin{abstract}
Introduction: Hematuria in patient with sickle cell disease (SCD) results from microthrombotic infarction in the vasa recta and peritubular capillaries of the renal medullar, with extravasation of blood in the collecting tubes.

Case description: These were 2 patients with heterozygous SCD with highly abundant macroscopic hematuria. The patients were 23 and 31 and had a clotting total hematuria. They were both anemic with good renal function. Cystoscopy had found bleeding from the left kidney in both patients. Uro-tomodensitometry and diagnostic uretero-renoscopy were without particularity for both patients. Treatment consisted of transfusions, oral rehydration, and hydergine for vaso-occlusive crisis.

Conclusion: Hematuria in heterozygous sickle cell disease can be massive. In our African regions, this case should be considered after having eliminated urothelium cancer.
\end{abstract}

\section{Keywords}

Hematuria, Sickle cell disease, Anemia

\section{Introduction}

In the urological context, the presence of red blood cells in the urine is linked to a lesion of the parenchyma or the urinary tract. This leads to the (micro or macroscopic) invasion of blood vessels, the contents of which will come into contact with the lumen of the urinary excretory tract [1].

What is particular in the SCD is that it results from micro-thrombotic infarctions in the vasa recta and peritubular capillaries of the renal medulla, with extrava- sation of blood in the collecting tubes. The origin of the bleeding can be bilateral, but the left kidney is most often involved. This predominance is due to an anatomical difference, since the left renal vein is longer than the right, which leads to an increase in venous pressure on the left side [1].

A hematuria should systematically be checked for urinary infection and/or papillary necrosis (NP), but also for medullary carcinoma of the kidney [2]. The objective of this study was to report two rare cases of massive hematuria in patients with SCD.

\section{Case Descriptions}

\section{Case 1}

It was a 23-year-old patient with type AS heterozygous sickle cell disease native and living in the city. He was referred from the nephrology department where he had been followed since April 2017, for the management of recurrent total clotting hematuria which had occurred suddenly.

In his history, a stay in a bilharzian endemic zone was noted.

He was in good general condition and the clinical examination was without particularity.

Paraclinically, there was anemia and the renal function was normal. The parasitolological and bacteriological examination of the urine as well as the urinary cytology were without particularities apart from the pres-

Citation: BAGAYOGO NA, SINE B, DIAW M, THIAM A, DIAO B, et al. (2021) Massive Hematuria in the Heterozygous Sickle Cell Disease: A Report of Two Cases. Int Arch Urol Complic 7:076. doi. org/10.23937/2469-5742/1510076

Accepted: March 08, 2021; Published: March 10, 2021

Copyright: (c) 2021 BAGAYOGO NA, et al. This is an open-access article distributed under the terms of the Creative Commons Attribution License, which permits unrestricted use, distribution, and reproduction in any medium, provided the original author and source are credited 
ence of high quantities of red blood cells. The Emmel test and hemoglobin electrophoresis confirmed AS SCD. The Cystoscopy revealed bleeding from the left ureteral meatus and the left diagnostic ureteroscope was normal. The Uro-tomodensitometry (CT scan) was also normal. Thus a hematuria of left renal origin on sickle cell disease was concluded. The management consisted of several iso group iso rhesus transfusions with catheterization and bladder lavage until the bleeding stopped. The patient had several blood transfusions to maintain hemoglobin levels within normal limits.

\section{Observation 2}

The second was a 31-year-old AS sickle cell patient known and monitored also living in the city. She came in for a sudden onset of total clotting hematuria.

She was in good general condition and the clinical examination was without particularities.

Para clinically, there was anemia at $10 \mathrm{~g} / \mathrm{dl}$, the renal function was normal. The parasitological and bacteriological examination of the urine and the urinary cytology were normal, apart from the presence of a high quantity of red blood cells. The Emmel test and hemoglobin electrophoresis confirmed AS sickle cell disease. The Cystoscopy revealed bleeding from the left ureteral meatus and the left diagnostic ureteroscope revealed red spots consistent with tubular necrosis lesions at the lower calici level. Uro-tomodensitometry (CT scan) was also normal apart from a simple 2-cm- diameter left renal cyst of type 1 Bosniak. Thus a hematuria of left renal origin on sickle cell disease was concluded. Its management consisted of oral rehydration, a prescription of iron in addition to its usual treatment for vaso-occlusive attacks based on Hydergine prescribed by the national blood transfusion center where she was monitored. We obtained an evolution resulting to the disappearance of hematuria.

\section{Discussion}

Hematuria in sickle cell disease is a complication whose frequency is little evaluated in our regions where bilharzia is endemic. Patients come for consultation only when hematuria is abundant and persistent because at this stage they feel worried but hematuria itself isn't considered a serious sign. Sickle cell disease is a hemoglobinopathy that often affects young Africans in general and particularly sub-Saharan Africans. Our patients were both young Senegalese. In the literature, the cases reported in Europe and in the world were from Africa. For example, with Verschuren, et al. in Belgium [3] the patient was 28-years-old and was African. In the study by Guédenon, et al. [4] the three patients were respectively 15, 16 and 21-years-old and were from Togo and in the study by Duvic, et al. in France [5] the mean age was 26.8 years (17-53 years), the population was made up of six men and four women and out of the $10 \mathrm{pa}$ tients one from Togo, one from Mauritania, one from
Cameroon, two from Martinique, two from Senegal and three from Guadeloupe.

Time spent before consultation is varied. In regions where bilharzia is endemic or hematuria is common, consultation time can be long. According to the authors, the time spent before consultation varies from 2 weeks to 3 years [3-5].

The information about one of our patients that he had bathed in a pond in a bilharzian endemic zone oriented our examination towards urinary bilharziasis. We did not find any history of hematuria in the sickle cell patient.

The hematuria reported by the various authors was total and clotting [3]. All patients with sickle cell disease, whether homo or heterozygous, can experience hematuria. However, the heterozygous AS form is more commonly reported [1,3].

The increased blood viscosity of the bone marrow due to intra-capillary falciformation leads to vasa recta thrombosis. These micro-thromboses are sometimes complicated by hematuria due to capillary rupture, kidney infarction, or papillary necrosis, which sometimes cause pain [1].

In addition, stronger renal venous pressure on the left due to the length of the renal vein and the presence of the venous crossroads might be the cause of the predominance of hematuria at the left [1].

Uro-CT is the key test for renal complications during sickle cell disease [1]. Diagnostic ureteroscopy is then performed to eliminate or search for a tumor of the upper excretory tract.

There is no specific treatment for the management of hematuria in sickle cell disease.

The management consists first of combating the factors that trigger the crisis.

Rest and the intake of alkaline beverages are used by some specialist to stop the hematuria. Drug treatment with epsilon-aminocaproic acid can also be used [5].

For the rest of the treatment, it is purely symptomatic. It consists of bladder lavage to prevent bladder clotting, blood transfusion $[3,4]$.

Hydroxyurea and blood transfusion are strongly recommended for many people with sickle cell disease [6].

Although the evolution is often favorable, the recurrences of hematuria are frequent hence the need to avoid the factors that trigger vaso-occlusive crises.

\section{Conclusion}

Hematuria due to SCD can have a worrisome picture for both the patient and the caregiver. Its association with clots and its occurrence in endemic bilharzian areas should lead to a search for urinary tract tumor. 


\section{References}

1. Raynal G, Bracq A, Tillou X, Limani K, Petit J (2007) Les complications rénales de la drépanocytose. Prog Urol 17: 794-795.

2. Yeche S, Rebillard X, Reynaud D, Dubois A (1996) Une cause rare d'hématurie: La drépanocytose hétérozygote. Rev Med Interne 17: 602.

3. Verschuren, F, ThysF, Wa I KK (2008) Une étiologie inhabituelle d'hématurie macroscopique en salle d'urgence: la nécrose papillaire rénale chez le patient drépanocytaire hétérozygote. Journal Européen des Urgences 21: 70-73.
4. Guedenon KM, Gbadoe AD, Nouwakpo NB (2015) Hématurie macroscopique dans la drépanocytose majeure au CHU Sylvanus-Olympio de Lomé (Togo). Médecine et Santé Tropicales 25: 432-433.

5. Duvic C, Bordier L, Hertig A, Ridel C, Didelot F, et al. (2002) Hématurie macroscopique révélant une drépanocytose hétérozygote: A propos de dix observations. La Revue de Medecine Interne 23: 690-695.

6. Yawn BP, Buchanan GR, Afenyi-Annan AN, Balla KS, Hassel LK, et al. (2014) Management of sickle cell disease: Summary of the 2014 evidence-based report by expert panel members. JAMA 312: 1033-1048. 